Anuario de la Facultad de Derecho. Universidad de Extremadura 35 (2019): 85-102 ISSN: 0213-988X - ISSN-e: 2695-7728

Doi: https://doi.org/10.17398/2695-7728.35.85

\title{
LA NATURALEZA Y LAS FASES DEL INFORME DE LA ADMINISTRACIÓN CONCURSAL
}

\section{THE NATURE AND PHASES OF THE BANKRUPTCY ADMINISTRATION REPORT}

\author{
TOMÁS CUÉLLAR MONTES \\ Universidad de Extremadura
}

Recibido: 13/02/2019 Aceptado: 18/o9/2019

\section{RESUMEN}

El informe de la administración concursal es un documento en el cual se plasma toda la información necesaria del concurso, en el aparecen el inventario de los bienes y la lista de los acreedores, pero este documento no es estático, sino que evoluciona con el tiempo, estando sujeto a plazos hasta llegar a su versión definitiva, a la que se llega después de hacer las correspondientes modificaciones en el inventario y en la lista de acreedores. Este informe es fundamental para que se alcancen los fines del concurso. Con este artículo se pretenden analizar las características de esta obligación legal, y las distintas fases por la que va pasando su elaboración.

Palabras clave: administración concursal, inventario y lista de acreedores, fases del procedimiento, modificaciones del inventario y de la lista de acreedores.

\section{ABSTRACT}

The banckrupcy administration report is a document that contains the whole information about the bankrupcy procedure, it contains the inventory and the list of creditors, but that document don't remains the same along the time, rather than that, it evolves, being subject to time frames, until it reaches it's final 
version, after the modifications of the inventory and the list of créditors. This report contains everything crucial for ataining the goals of the bankrupcy procedure. This article analyse the characters of this legal obligation, and the diferent phases of it's making.

Keywords: bankrupcy administration, inventoy and list of creditors, phases of the procedure, modifications of the inventoy and list of creditors.

Sumario: 1. Introducción. 2. Naturaleza y plazos del informe. 3. Fases del informe: 3.1. Fase previa; 3.2. Fase de presentación del informe inicial; 3.3. Fase de impugnación del informe; 3.4. Fase del informe final del concurso. 4. Conclusiones.

\section{INTRODUCCIÓN}

De entre las funciones orgánicas ${ }^{1}$ de la administración concursal, podemos entender que la elaboración del informe concursal es sin duda la tarea por antonomasia, dado que con esta concluye la fase común ${ }^{2}$. Pero al mismo tiempo, expone de forma clara las informaciones más relevantes para quienes forman parte de este procedimiento en la medida que expone un reflejo fiel de la composición de las masas activa y pasiva y al mismo se le une un "escrito", en expresión de la norma ${ }^{3}$. En él se pone de manifiesto la evaluación que la administración concursal realiza de las propuestas de convenio. Además, para el caso de que se estime la necesidad de liquidar, se expone el plan de liquidación. En definitiva, tanto en un caso como en otro los administradores exponen su parecer sobre lo que ha de hacerse, bien entendido, que a todo lo anterior se una también una valoración de la empresa y de las unidades productivas que la integran en ambos supuestos.

\footnotetext{
1 Jesús Conde Fuentes, "La impugnación de inventario y de la lista de acreedores (provisional y definitiva)". Revista General de Derecho Procesal 33 (2014), https://www.iustel.com/v2/revistas/detalle_revista.asp?id_noticia $=414527$

2 Francisco José Alonso Espinosa, "El informe de la administración concursal: un intento de clarificación sistemática", Revista de Derecho Concursal y Paraconcursal 19 (2013): 101.

3 Ley 22/2003, de 9 de julio, Concursal. (BOE, núm. 164 de 10 de julio de 2003), art. 75.
} 
De todo lo expuesto, se puede entender fácilmente que se trata del documento más importante para un acreedor (no lo es menos para el concursado), dado que a la vista de lo expuesto podrá empezar a figurarse cómo va a ver satisfechos sus créditos, en el caso de que esto sea posible o, por el contrario, como se va a liquidar la empresa; lo que en principio le va a indicar en cuánto va a ver satisfechas las deudas pendientes.

Además, tanto en el caso de la masa activa, en la cual aparecen reflejados tanto el inventario como el avaluó de los bienes del concursado, como en el caso de la masa pasiva, en la cual aparecen tanto la lista de acreedores como la clasificación de sus créditos, nos encontramos ante la piedra de toque de este procedimiento ${ }^{4}$. Lo que es más importante, desde el punto de vista práctico, el origen de una buena parte de las controversias que puede generar un concurso de acreedores.

\section{NATURALEZA Y PLAZOS DEL INFORME}

Estamos ante una obligación legal para los administradores, como aparece recogida en el artículo 33 de la ley concursal ${ }^{5}$. Pero debemos entender que aquí no estamos ante un informe, entendido como los informes que los administradores sociales presentan a las juntas generales de las sociedades, en las que en el caso de las cuentas, éstas deben sujetarse a normativas contables. En este caso, es la normativa del concurso la que en el art. 75 establece los contenidos del informe; por tanto, sus contenidos deben sujetarse a lo previsto en la norma concursal.

Se trata además de un documento con múltiples destinatarios, entre ellos y como figura señera, el juez del concurso, que en definitiva será el que garantice que el órgano de administración concursal ha cumplido

\footnotetext{
4 Rafael Gimeno-Bayón Cobos y Jacinto Gimeno Valentin-Gamazo, "Algunas cuestiones sobre la comunicación de créditos concursales", Revista de derecho concursal y paraconcursal: Anales de doctrina, praxis, jurisprudencia y legislación 12 (2010): 219-253.

5 Ley 22/2003, de 9 de julio, Concursal. (BOE núm. 164 de 10 de julio de 2003), art. 33.1.e "Presentar al juez el informe previsto en el artículo 75."
} 
correctamente sus obligaciones. Además, están el resto de los interesados a los que también se destina este informe, empezando por el concursado/a y su cónyuge, sus socios y acreedores, sin olvidar aparceros y arrendatarios de bienes del concursado y así un largo etcétera de quienes tengan una relación con él y sus bienes.

De la obligación de presentar el informe, nace como no podía ser de otra manera, la necesidad de emplazar este mandato, y aquí la ley distingue entre dos plazos el correspondiente al concurso ordinario y el aplicable al concurso abreviado. En el primer caso, estamos hablando de un plazo de dos meses ${ }^{6}$ y en el segundo, de un plazo de 15 días ${ }^{7}$. El inicio de estos períodos comienza a partir de la fecha de aceptación del cargo por el administrador y en el caso de que haya dos administradores, a partir de la aceptación del último de ellos.

Los administradores tienen un plazo de cinco días para aceptar el cargo, a partir del momento en que les sea comunicado el nombramiento, esto viene a paliar la práctica que existía en la antigua ley de suspensión de $\operatorname{pagos}^{8}$, consistente en que los interventores judiciales demoraban la aceptación del cargo, como manera de ganar tiempo a la hora de elaborar el dictamen, y así evitaban el incumplir los plazos de presentación".

No debemos olvidar que, como paso previo, existe un período de alegaciones anterior a la formulación del informe que trata de evitar errores en el informe en la medida en que permite a los acreedores durante un período de tres días, realizar alegaciones sobre aspectos no jurídicos ${ }^{10}$. Esta obligación lleva aparejadas responsabilidades ya que la inactividad de la administración del concurso puede acarrear la exigencia de las correspondientes responsabilidades con el cese en el cargo, así como la

\footnotetext{
6 Ley 22/2003, de 9 de julio, Concursal. (BOE núm. 164 de 10 de julio de 2003), art. 74.1

7 Ley 22/2003, de 9 de julio, Concursal. (BOE núm. 164 de 10 de julio de 2003), art. 191.1

8 Ley de 26 de julio 1922, de Suspensión de pagos. (GACETA de 14 de septiembre de 1922)

9 Jorge Noval Pato, El informe de la administración concursal (Madrid: La Ley, 2008), 67

10 Alonso Espinosa, "El informe...", 105.
} 
imposibilidad de cobrar los honorarios pendientes incluyendo la devolución de los percibidos ${ }^{11}$.

Sin embargo, la complejidad de los informes y el volumen de datos que supone en muchos casos su elaboración han obligado al legislador a establecer períodos de prórrogas tanto en el caso del concurso ordinario como en el caso del concurso abreviado. Para el concurso ordinario se establece un primer período de prórroga que será por dos meses máximo y a criterio del juez, previa petición que hará la administración concursal. Esto siempre que sea hecha antes del vencimiento del plazo inicial de 2 meses, y que deberá fundamentarse en la existencia de circunstancias excepcionales; aunque con una particularidad, que no es otra que a los administradores concursales que tengan tres o más concursos en tramitación no podrán solicitarla salvo alegando causas ajenas a su ejercicio profesional.

El legislador intenta evitar que estos profesionales aleguen de manera habitual el volumen de trabajo o la insuficiencia de recursos materiales o humanos, como consecuencia del volumen de trabajo. Por lo tanto, quedan así en este caso limitadas estas peticiones a cuestiones de fuerza a mayor o de índole personal ${ }^{12}$. En el caso del concurso abreviado la prórroga del plazo de presentación del informe será de quince días hábiles y deberá fundamentarse la petición en razones objetivas.

En el caso del concurso ordinario, a esa primera prórroga le es acumulable otra prórroga más, previa petición de la administración

11 SAP LU 446/2013 del 20 de junio de 2013 "CUARTO.- Como quiera que la consecuencia jurídica prevista en el art. 74.3 de la Ley Concursal encierra una sanción cual es la perdida de la remuneración (el trabajo se habría realizado, pero la extemporaneidad comportaría la sanción de la pérdida al derecho a su cobro), para poder establecer la misma tendría que acreditarse la concurrencia del supuesto de hecho, y de lo expuesto no puede apreciarse así, antes al contrario, se desprende indiciariamente que si el plazo vencía el 10 de febrero de 2012 y el informe se presenta el 3 de febrero, el mismo se evacua dentro del plazo de la prórroga. Por otra parte, no puede ir la Sala más allá de la diligencia final ya acordada, pues ello comportaría perderla imparcialidad objetiva que corresponde al Tribunal en una cuestión no sometida al interés público sino al interés privado de las partes contendientes en plano de igualdad. En definitiva, ante la falta de acreditación de la existencia indebida de varias prórrogas, y de la presentación extemporánea del informe de la Administración Concursal, se está en el caso de confirmar la sentencia apelada".

12 Alonso Espinosa, "El informe...", 104. 
concursal y siempre por decisión del juez del concurso, debiendo darse una circunstancia, que es la existencia de un número de acreedores superior a dos mil. En caso de ser concedida, el juez fijará la duración de la misma, que en ningún caso superará los cuatro meses ${ }^{13}$.

\section{FASES DEL INFORME}

\subsection{FASE PREVIA}

Me he referido anteriormente a la obligación legal ${ }^{14}$ por parte de la administración concursal de comunicar extraoficialmente, partes del informe, concretamente tanto de la lista de acreedores, como del proyecto de inventario, si bien en mi opinión, hubiera sido mucho más interesante haber calificado a ambos de "proyecto de informe", en la medida que se trata de formulaciones, que precisamente se someten a esta información, al objeto de depurarlas.

Se trata esta de una obligación introducida en la reforma de $2011^{15} \mathrm{y}$ sugerida por la doctrina ${ }^{16}$, y que sin duda obedece a una necesidad de evitar un rio de impugnaciones como consecuencia de errores aritméticos y omisiones, que antes de esta reforma solo podían resolverse por medio de impugnaciones, lo que en la práctica dilataba enormemente el procedimiento, ya que era necesario resolver todas estas cuestiones para poder llegar al informe definitivo y por tanto, parecía aconsejable que

13 Ley 22/2003, de 9 de julio, Concursal. (BOE núm. 164 de 10 de Julio de 2003), art. 74.3.

14 Ley 22/2003, de 9 de julio, Concursal. (BOE núm. 164 de 10 de Julio de 2003), art. 95 1. "La administración concursal, con una antelación mínima de diez días previos a la presentación del informe al juez, dirigirá comunicación electrónica al deudor y a los acreedores que hubiesen comunicado sus créditos y de los que conste su dirección electrónica, informándoles del proyecto de inventario y de la lista de acreedores, estén o no incluidos en la misma. La misma comunicación se publicará en el Registro Público Concursal. Los acreedores podrán solicitar a la administración concursal, igualmente por medios electrónicos, hasta tres días antes de la presentación del informe al juez, que se rectifique cualquier error o que complementen los datos comunicados. La administración concursal dirigirá igualmente por medios electrónicos una relación de las solicitudes de rectificación o complemento presentadas al deudor y a los acreedores, la cual será también publicada en el Registro Público Concursal".

15 Ley 38/2011, de 10 de octubre, de reforma de la Ley 22/2003, de 9 de julio, Concursal. (BOE núm. 245 de 11 de octubre de 2011) Art. 95.

16 Noval, El informe ..., 220. 
fuera la propia administración, la que a instancias de los afectados corrigiera estos defectos. No aparecen claramente en el texto de la ley, las consecuencias que pueden acarrear a los administradores el incumplimiento de esta obligación, más allá, de la que se puedan derivar de eventuales reclamaciones exigiendo su responsabilidad civil por los perjuicios dimanantes de esta falta de actividad.

De manera a mi juicio novedosa, tanto las informaciones a los acreedores como la formulación de alegaciones se hace manera electrónica y una vez resueltas por la administración concursal, son comunicadas a los acreedores a su dirección de correo electrónico ${ }^{17}$, siempre que esta conste, independientemente del inserto que se hace en el Registro Público Concursal.

En definitiva, los administradores deben en función de la diligencia que les es exigible, proceder a las correcciones o por el contrario rechazarlas, pero de manera motivada, ahora bien, es necesario a la hora de entender la manera de llevar a cabo estas subsanaciones, que del tenor literal del precepto se deduce que estas están referidas necesariamente a errores sobre créditos de los que no solo han sido ya comunicados en tiempo y forma, sino que además, se trata de créditos sobre los que la administración tiene documentación ( en el texto legal se usa la expresión datos comunicados). Lógicamente y a tenor de lo ya dicho, no cabe usar esta fase para la comunicación de nuevos créditos.

\subsection{FASE DE PRESENTACIÓN DEL INFORME INICIAL}

En este caso nos encontramos ya ante el cumplimiento efectivo de la obligación legal que la administración tiene de presentar el informe al juez, asunto este que es notificado a las partes personadas y publicado en el Registro Público Concursal. Es necesario entender que en realidad la

17 Esta disposición ha sido redactada en 2015 dentro de las reformas que introdujo la Ley 9/2015, de 25 de mayo, (BOE núm. 125 de 26 de mayo de 2015) de medidas urgentes en materia concursal. 
notificación es no tanto con la idea de facilitar a las partes una copia del documento, como el poner en su conocimiento que efectivamente se ha puesto a disposición de S.S $\mathrm{S}^{\mathrm{a}}$ el informe, y esto es así, en la medida que la norma establece que las partes obtendrán copias a su costa, de lo que se deduce que no se les facilita, si bien es cierto que en uso de las facultades que le atribuye al juez el artículo 95.3, el juez podría ordenar su publicación, en este caso en la página web de la sociedad, o en otro medios que se estimaran convenientes.

\subsection{FASE DE IMPUGNACIONES DEL INFORME}

Las acciones de impugnación se limitan por ministerio de la ley exclusivamente a dos elementos; el inventario y la lista de acreedores.

La impugnación del inventario tan solo puede ir a la inclusión ${ }^{18} \mathrm{o}$ exclusión de bienes o derechos, o a obtener el aumento o la disminución en el avaluó de los mismo. El avaluó debemos entenderlo en un sentido amplio, en la medida en que se han de incluir las acciones de impugnación sobre otras cuestiones que tienen influencia en los bienes, como puede ser el caso de datos registrales, o la existencia de derechos reales, lo cual lleva implícitamente, que mediante la impugnación puede solicitarse la modificación en la valoración del avaluó que figure en el inventario ${ }^{19}$.

Además de lo ya expuesto en materia de inventario conviene no olvidar que también es objeto de impugnación la lista de acreedores, donde se discute no solo la inclusión o exclusión de los créditos, sino que

18 STS 430/2014, de 24 de julio de 2014"En cuanto al evalúo que se solicita señaló que es un deber de la AC y a ella corresponde destacar las características de la finca a tenor del art. 82.3 LC. En cuanto a la inclusión de las fincas, una de ellas con doble inmatriculación (local almacén y local comercial), señala que parece evidente que existe una cierta descoordinación entre el inventario y el plan de liquidación que se ha presentado, discordancia que impone su rectificación; y en cuanto a la omisión de las dos fincas, por el hecho de no ser fincas registrales, es contrario al art. 76 LC que establece que la masa activa está formada por bienes y derechos integrados en el patrimonio del deudor. La inmatriculación registral de las fincas, dice, es optativa en nuestro sistema registral, lo que puede afectar a la valoración de las mismas, pero en absoluto a su existencia, por lo que declara que procede incluirlas en el inventario. Por todo ello consideró que las tres fincas debían incluirse en el inventario, sin perjuicio de la valoración que le atribuya la administración concursal”.

19 Noval, El informe ..., 200. 
además se discute su correcta clasificación ${ }^{20}$ y su cuantía. Si bien algunos créditos están específicamente excluidos del ámbito de la impugnación, ya que deben estar incluidos obligatoriamente en la lista de acreedores, en este caso será la actividad de la propia administración concursal la que deberá en procedimientos fuera del ámbito concursal impugnar estos créditos ${ }^{21}$.

Finalmente, la jurisprudencia ha admitido la posibilidad por parte del juez, de incluir créditos no contemplados en la lista de acreedores, por no haber sido comunicados oportunamente, lo cual va más allá de la mera corrección de errores, que en un principio parecía ser el fin de este procedimiento $^{22}$.

Es interesante comprobar la legitimación activa y pasiva en este caso. Cuando se trata de legitimación activa, el artículo 96.1 establece dos categorías de legitimados; por un lado, las partes personadas en la sección

20 STS 372/2018, de 20 de junio de 2018“Esta cuestión ha sido abordada en varias sentencias de este tribunal, entre otras, las citadas sentencias 629/2015, de 17 de noviembre, y 630/2015, de 18 de noviembre. En ellas afirmamos que el swap no es un contrato que produzca obligaciones recíprocas entre las partes sino obligaciones para una sola de las partes en cada una de las liquidaciones previstas, sin perjuicio de que el riesgo sea bilateral y por la aleatoriedad propia de este contrato puede que la parte para la que surgen obligaciones no sea la misma en todas las liquidaciones.

Por tal razón, es doctrina jurisprudencial que «los créditos derivados de contratos de permuta financiera en que el deudor se encuentre en concurso son créditos concursales y no contra la masa, con independencia de que se hayan devengando antes o después de la declaración de concurso".

21 Ley 22/2003, de 9 de julio, Concursal. (BOE núm. 164 de 10 de julio de 2003) Art. 86.2 "Se incluirán necesariamente en la lista de acreedores aquellos créditos que hayan sido reconocidos por laudo o por resolución procesal, aunque no fueran firmes, los que consten en documento con fuerza ejecutiva, los reconocidos por certificación administrativa, los asegurados con garantía real inscrita en registro público, y los créditos de los trabajadores cuya existencia y cuantía resulten de los libros y documentos del deudor o por cualquier otra razón consten en el concurso. No obstante, la administración concursal podrá impugnar en juicio ordinario y dentro del plazo para emitir su informe, los convenios o procedimientos arbitrales en caso de fraude, conforme a lo previsto en el artículo 53.2, y la existencia y validez de los créditos consignados en título ejecutivo o asegurados con garantía real, así como, a través de los cauces admitidos al efecto por su legislación específica, los actos administrativos".

22 STS 3384/2011 de 13 de mayo de 2011. "Sin embargo, es evidente que la regla primera del artículo 92, además de referirse a los créditos "comunicados tardíamente [...]incluidos por la administración concursal en la lista de acreedores ", se refiere a los que, "no habiendo sido comunicados oportunamente ", puede incorporar a dicha lista " el Juez al resolver sobre la impugnación " de la misma. Con lo que abre al intérprete una segunda posibilidad: la de entender que los créditos pueden ser incluidos en la lista por el Juez al decidir sobre su impugnación, aunque no hubieran sido comunicados antes - y, claro está, no resultaren de los libros o documentos del deudor ni constaren en el concurso de otro modo. Esta segunda es la interpretación que nos parece la adecuada". 
cuarta del concurso, pero además incluye una categoría indefinida, a la que califica como "demás interesados" que incluye a todo tipo de acreedores $^{23}$ y que la propia jurisprudencia ha venido matizando considerándola en un primer momento de una manera muy amplia ${ }^{24}$ en y que posteriormente ha matizado en el sentido de que debe tratarse de un interés propio, y que en nada incluye a un interés abstracto, como podría ser un interés en que los informes sean realizados correctamente, es decir es necesario que exista un nexo de causalidad. Bien es cierto que ese nexo causal sí admite interpretaciones curiosas; así Noval Pato pone el ejemplo de los trabajadores de una empresa que impugnan el inventario o la lista de acreedores al objeto de evitar, que los errores puedan perjudicar una posible recuperación de la empresa ${ }^{25}$.

Entre los legitimados cabe preguntarse el caso del deudor y el de la administración concursal. En el caso del deudor, es obviamente una parte en el procedimiento y existen pronunciamientos en este sentido ${ }^{26}$;

23 Conde Fuentes, "La impugnación de inventario...”.

24 Sentencia Civil No 595/2007, Juzgados de lo Mercantil - Bilbao, Sección 1, de 19 de diciembre de 2007 "El art. 96.1 LC permite que quien tiene un interés en la formación de las masas del concurso, particular y ajeno al concurso, pero relacionado con él, pueda discutirlas a través del cauce del incidente concursal, aunque no sea acreedor o deudor del concurso. Quien se pretende propietario de un bien incluido en la masa activa, el cónyuge del concursado, los obligados solidariamente con aquel a responder frente a acreedores comunes, pretendidos acreedores excluidos del informe que formalmente no tienen por ello la cualidad de tales, terceros que podrían verse afectados por las acciones rescisorias que se insinúan en el informe, posibles cesionarios de créditos, personas especialmente relacionadas, el propio concursado según la SAP Madrid, Secc. $28^{\mathrm{a}}, 15$ febrero 2007, AC 2007\948, e incluso, según alguna doctrina (Cazquez Albert), la propia administración concursal cuando percibe errores que deben rectificarse, son entre otros, posibles interesados que tienen legitimación en atención a su interés particular. En este caso el adquirente de un bien que era de la concursada, gravado con una hipoteca por un crédito contra la concursada que ostenta un tercero, tercero que según la administración concursal podría ser persona especialmente relacionada con el concursado, tiene interés, particular pero legítimo, en la calificación de dicho crédito, colmando la condición de "interesado" del art. 96.1 LC. Su interés, particular sin duda, tiene que ver con la subsistencia o no de la hipoteca, que podría comprometerse por la calificación como subordinado el crédito del acreedor hipotecario. En el caso de los ex trabajadores su interés deriva de que a través de una sociedad son en la actualidad inquilinos de la finca. Por lo tanto, todos ostentan un interés que merece la consideración de legítimo".

25 Noval, El informe..., 199.

26 AAP A 97/2012 de 24 de mayo de 2012 "Lo que se debate es si la concursada está legitimada, al amparo del artículo 96-1 de la Ley Concursal, para impugnar la lista de acreedores con independencia de su sentido, es decir, al margen de sicón dicha impugnación se pretende, como parece lo más lógico, negar la condición de acreedor a alguno delos reconocidos por la Administración concursal, discrepar, por exceso de la cuantía de algún crédito o de la más privilegiada calificación reconocida o si, por el contrario, también se pretendiera mejorar el status de un acreedor bien mediante su reconocimiento, bien en relación al crédito reconocido. Es decir, se debate si la 


\section{sin embargo, estas impugnaciones deben siempre mirarse desde la pers- pectiva del interés legítimo, pues a veces puede detectarse que por parte}

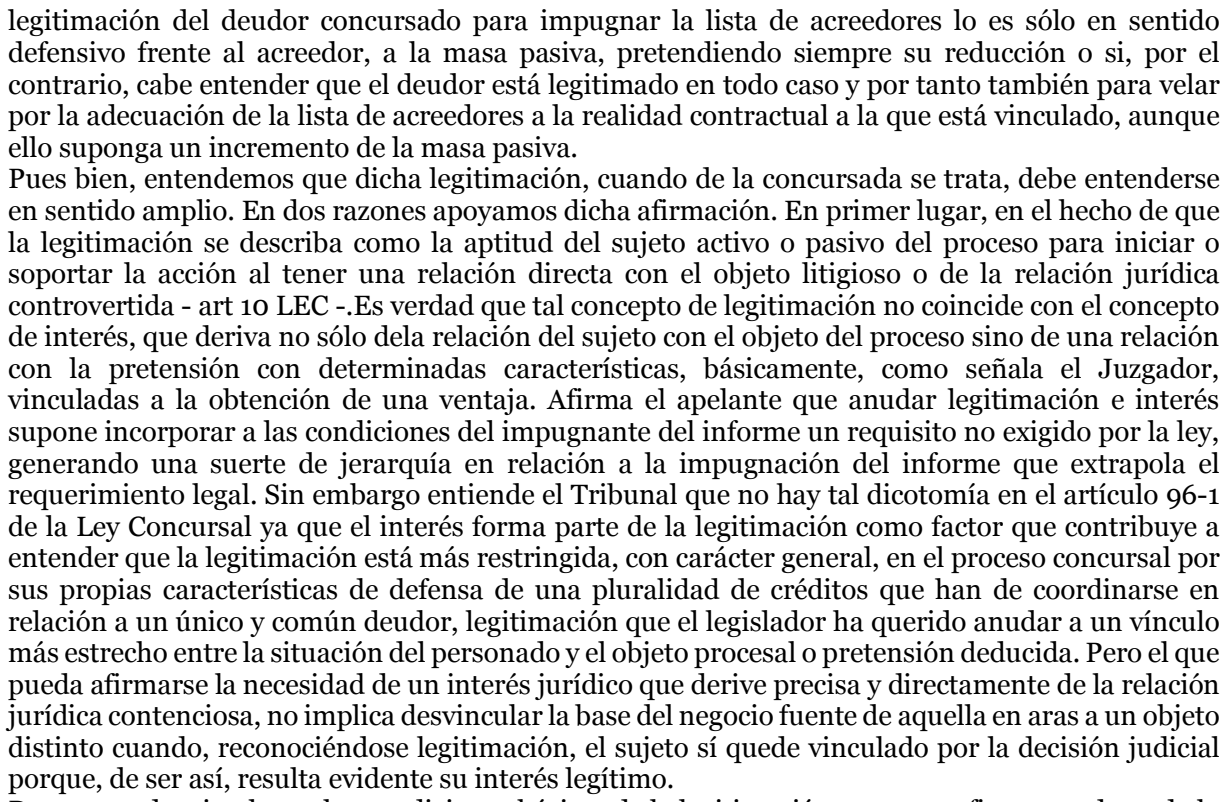
De este modo, sin alterar las condiciones básicas de la legitimación que se confiere cuando se da la relación a que se refiere el artículo 10 de la Ley de Enjuiciamiento Civil, sí se acota a las condiciones propias del proceso concursal, tal vinculación, evitando litigiosidad sin verdadera afinidad con el litigante. La consecuencia de cuanto se indica es que no puede negarse interés al concursado en la impugnación por la exclusión de un acreedor, porque, primero, formula pretensión en el marco de una relación en la que el concursado es parte, segundo, el objeto específico de la impugnación recae sobre un acreedor reconocido como tal en el listado aportado en su día por el deudor, conforme a lo previsto en el artículo 6-2-4 de la Ley Concursal y, tercero, tal acreedor presunto tiene una especial relación con la concursada, de la que es socio relevante del deudor al punto que en el listado de acreedores presentado por la deudora se había calificado, al amparo del artículo 93 de la Ley Concursal, como acreedor subordinado, al ser socio con más del 10\% delas acciones de la misma. La segunda razón que apoya la legitimación del concursado trae razón de ser en la relación existente entre la masa pasiva y el concurso - art $49 \mathrm{LC}$ - y entre la masa pasiva y el deudor al que se le imponen específicos deberes - art $6,42,45 \mathrm{LC}$ - destinados a una completa y veraz determinación de las masas, relaciones que sí hacen extrapolar el interés de la exactitud y veracidad de la masa pasiva, por quedar conectado con el fin mismo del concurso, hasta alcanzar la categoría de interés/deber específico del deudor en la exactitud de la determinación de las masas. En conclusión, la legitimación en la impugnación de la lista de acreedores deviene ineludible en la parte concursada ya que al formalizar su pretensión frente a la lista de acreedores para que se incluya, con una determinada calificación, un crédito, además de dar cumplimiento, por otros mecanismos, a sus deberes de información, lo que solicita es una sentencia que, en relación a un derecho de crédito propio y a una determinada situación jurídica -la que dimana del listado de acreedores-, modifique la misma en base a la relación crediticia que mantiene con el acreedor y por tanto, a que la lista de acreedores revista veracidad, completud y exactitud y en ello no sólo hay genérica legitimación sino evidente interés". 
del deudor se atienden a otros intereses en perjuicio de los demás acreedores $^{27}$.

En lo tocante a la administración concursal, es obviamente parte en el concurso, pero no para impugnar su propio informe, situación está ciertamente rocambolesca, ni siquiera cuando el interés legítimo sea la corrección de sus propios errores ${ }^{28}$.

En lo tocante a la legitimación pasiva, esta deberá dirigirse contra la administración concursal, que es la autora del informe, contra el concursado (la mayor parte de las veces) y contra aquellos acreedores a los que afecta directamente la impugnación en tanto parte de un "litis consorcio pasivo necesario". Sobre este último asunto ni la doctrina ni la jurisprudencia son pacíficas ${ }^{29}, \mathrm{y}$ hay pronunciamientos a favor y en contra, en la medida, que existen quienes sostienen que la legitimación pasiva no debe entenderse aplicable a cualquiera por el mero hecho de que pueda perjudicarse por estimarse una impugnación, ya que genéricamente la administración concursal como parte demandada defiende la veracidad y exactitud del informe y por tanto defiende los intereses de todos los acreedores reconocidos ${ }^{30}$, pero al mismo tiempo existen resoluciones

27 SAP MU 300/2013, de 31 de enero de 2013.

28 SAP Z 2077/2007 de 17 de diciembre de 2007 "Respecto a la "autoimpugnación" del propio informe, la cuestión resulta dudosa. Ciertamente quenada dice la ley de forma expresa ni a favor ni en contra de dicha impugnabilidad por la autora del mismo. La estructura de la mecánica concursal parece dar a entender que la A.C. tiene encomendada una misión como órgano del concurso y que ha de realizar dentro de unas formas y unos plazos. Es su actividad la que puede ser jurídicamente atacada por los "interesados" que no coincidan con los criterios y decisiones de la A.C. La "autoimpugnación" de su propio informe, más parecería una anulación parcial de oficio con audiencia de interesados. Considera esta Sala que la A.C. no está dentro del concepto de "interesado" a que se refiere el Art. 96 de la Ley Concursal. Carecería de sentido toda la redacción legal relativa a traslados y comunicaciones, innecesarios cuando el "interesado" es el propio emisor del informe. Es verdad que la Ley Concursal no prevé ningún mecanismo de corrección "de oficio" de las ausencias del informe. Pero también hay que entender que toda ley procedimental, o en los preceptos de carácter instrumental, se recogen unas pautas de "forma" y "tiempo" imprescindibles para la seguridad jurídica que, no olvidemos, es un principio constitucional (art. 9-3 de la C.E.). La función de la A.C. respecto al "informe", determinación de la Masa Activa y Pasiva concluye con la presentación del "informe" al juzgado en el plazo y forma que estipulan los Arts. 74 y 75 de la Ley Concursal. A partir de ahí, los desacuerdos los podrán manifestar quienes no elaboraron dicho informe".

29 Laura Ruiz Monge y Luis Franco Betegón "La legitimación pasiva en la demanda incidental de impugnación del informe de la administración concursal”, Diario La Ley $\mathrm{n}^{0} 7466$ (2010)

30 SAP B 15815/2004 de 13 de octubre de 2004 "El recurso del Ayuntamiento de Girona se basa, en síntesis, en la innecesariedad de su llamada al litigio. Cierto es que la súplica de la demanda no 
jurisprudenciales que consideran a todos los acreedores legitimados pasivamente, simplemente por el mero hecho de serlo ${ }^{31}$.

Existe, además, la posibilidad de que el resto de partes personadas en el concurso puedan intervenir en los incidentes como coadyudantes ${ }^{32}$.

\subsection{FASE DEL INFORME FINAL DEL CONCURSO}

El art. 96.5 de la Ley concursal establece la obligación de la administración concursal de introducir todas las modificaciones que se hubieran producido como consecuencia de haberse estimado alguna o algunas de las impugnaciones. Así, el tenor literal de la norma dispone:

"Se harán constar expresamente las diferencias entre el inventario y la lista de acreedores inicialmente presentados y los textos definitivos, así como relación de las comunicaciones posteriores presentadas y las modificaciones incluidas y otra actualizada de los créditos

afectaba los intereses de la Corporación municipal de Gerona (por más que fuera adjudicataria de la finca NUMo10, que integraba la 558, pues la reintegración se dirige necesariamente a la finca 631, adjudicada a NUEVA BOLUETA en compensación resultante del expediente de reparcelación), y de ahí que el fallo de la sentencia no contenga pronunciamientos que deba acatar o combatir. Cierto aparece, por ello, que era innecesaria su llamada a litigio. Su falta de legitimación pasiva, por carencia de interés y afectación por el fallo determinará la imposición a la parte actora de las costas causadas por su comparecencia y defensa (inexistentes, por otra parte, ya que no compareció en la primera instancia)".

31 SAP SE 4271/2008 de 2 de diciembre de 2008 "La Caja de Ahorros San Fernando de Huelva Sevilla y Jerez compareció en forma en el proceso concursal de "Algodonera de Las Cabezas S.A." (fue el instante del citado concurso). Por tanto, está por este motivo legitimada para intervenir en el incidente, y el Juzgado tenía la obligación de emplazarle para contestar a la demanda incidental al estar personada en el concurso, como dispone el art. 194.3 de la LC. Es obvio que cuando este precepto regula el obligatorio emplazamiento de las partes personadas, se refiere a las personadas en el proceso concursal, pues en el incidente recién iniciado es claro que el único personado es el propio demandante. Así las cosas, la entidad acreedora comparecida en forma en el concurso no tiene que solicitar su intervención en el incidente utilizando el trámite del art. 13 de la LEC, sino que es el Juzgado el que tiene la obligación de emplazarle dándole la oportunidad de comparecer en el incidente y de contestar a la demanda si a su derecho conviene, o de adoptar en el mismo la posición que estime oportuna, coadyuvando ya con la parte que lo hubiese propuesto ya con la contraria. En el proceso concursal el acreedor no tiene que acreditar ningún interés legítimo para ser parte en el incidente. El interés se le presume, pues es evidente que tal interés existe dada su condición de acreedor concursal personado en los autos principales del proceso. No puede caber duda alguna de que un acreedor concursal tiene interés legítimo en cualquier incidente relativo a la calificación y reconocimiento de créditos que se suscite en el proceso concursal".

32 Ley 22/2003, de 9 de julio, Concursal. (BOE núm. 164 de 10 de Julio de 2003) Art. 193.2 "Cualquier persona comparecida en forma en el concurso podrá intervenir con plena autonomía en el incidente concursal coadyuvando con la parte que lo hubiese promovido o con la contraria". 
contra la masa devengados, pagados y pendientes de pago, con expresión de los vencimientos respectivos, todo lo cual quedará de manifiesto en la secretaría del juzgado".

A resultas de lo anterior se debe presentar la modificación de la exposición motivada del informe inicial, lo cual como es lógico se sustenta en el hecho de que las modificaciones en la situación patrimonial del concursado a resultas de las impugnaciones, pueden suponer un cambio en las circunstancias del concursado y por tanto el informe emitido en su día puede resultar desfasado ${ }^{33}$.

Desde un punto de vista procesal las impugnaciones se resuelven por el trámite de incidentes que la ley concursal prevé en el Capítulo Tercero del Título VIII (arts. 192 al 196), que en su última disposición establece, que las sentencias tendrán la consideración de cosa juzgada, en los términos previstos en el apartado primero del art. 222 de la Ley de Enjuiciamiento Civil ${ }^{34}$.

El legislador introdujo en su reforma de la ley concursal de 2011 la posibilidad de comunicar créditos existentes antes de la declaración de concurso, pero comunicados después de haberse emitido el informe inicial. Esto supone en la práctica que de acuerdo con lo dispuesto en el art. 96.bis ${ }^{35}$ el informe final del concurso dista de ser el último, y la cuestión es sencilla, de acuerdo con lo establecido en la meritada disposición, la administración deberá resolver sobre estos créditos en el informe final,

33 Conde Fuentes, "La impugnación de inventario..."

34 Ley 1/200o, de 7 de enero, de Enjuiciamiento Civil. (BOE núm. 7 de 08 de enero de 2000) Art. 222.1“La cosa juzgada de las sentencias firmes, sean estimatorias o desestimatorias, excluirá, conforme a la ley, un ulterior proceso cuyo objeto sea idéntico al del proceso en que aquélla se produjo".

35 Ley 22/2003, de 9 de julio, Concursal. (BOE núm. 164 de 10 de Julio de 2003) Art. 96 bis “1. Concluido el plazo de impugnación y hasta la presentación de los textos definitivos, se podrán presentar comunicaciones de nuevos créditos. Estos créditos serán reconocidos conforme a reglas generales y en su clasificación se estará a lo dispuesto en el artículo 92. 1. Salvo que el acreedor justifique no haber tenido noticia antes de su existencia, en cuyo caso se clasificarán según su naturaleza. 2. La administración concursal resolverá sobre ellas en la lista de acreedores definitiva a presentar. 3. Si dentro del plazo de diez días siguiente a la puesta de manifiesto de los textos definitivos se formula oposición a la decisión de la administración concursal sobre las comunicaciones posteriores presentadas, se le dará la tramitación del incidente concursal. Esta impugnación no impedirá la continuación de la fase de convenio o liquidación, siendo de aplicación lo previsto en el artículo 97 ”. 
ahora bien se abre una vez presentado este informe un plazo de impugnación a estas inclusiones, lo cual viene a poner en duda este apelativo de "final", ya que obviamente habrá que estar al resultado de la resolución de estos incidentes. Por otra parte, las modificaciones producto de estas impugnaciones solo se podrán introducir antes de la resolución que apruebe la propuesta de convenio o antes de que se presenten los informes de los artículos 152 (informes sobre liquidación) y 176 bis (conclusión por insuficiencia de la masa activa).

Podríamos pensar que a tenor de lo expuesto tan solo pueden impugnar el informe final los titulares de créditos comunicados tardíamente, pero lo cierto es que no son los únicos ya que la ley prevé otras excepciones en el caso de presentación de créditos después de la emisión del texto definitivo, como son los siguientes casos:

- Cuando después de la presentación del informe final se inicie un procedimiento administrativo de comprobación o inspección del que pueda resultar créditos de Derecho público de las Administraciones públicas y sus organismos públicos.

- Cuando se inicie un proceso penal o laboral que pueda suponer el reconocimiento de un crédito concursal.

- Cuando se hubiera cumplido la condición o contingencia prevista o los créditos hubieran sido reconocidos o confirmados por acto administrativo, por laudo o por resolución procesal firme o susceptible de ejecución provisional con arreglo a su naturaleza o cuantía.

En todos estos casos, los créditos una vez reconocidos, serán clasificados de acuerdo con su naturaleza sin que quepa el considerarlos subordinados. 


\section{CONCLUSIONES}

$\mathrm{Al}$ reflexionar sobre el informe de la administración concursal debemos tener presente la complejidad que encierra este procedimiento y esto en varios sentidos de una parte, los concursos, suelen incluir a un gran número de personas, $\mathrm{y}$, de otra parte, la complejidad que implica relacionar correctamente deudas y activos. Todo esto choca con dos escollos:

El primero es el tiempo, es cierto que se pueden pedir prorrogas, pero aun así a mi juicio los plazos son cortos, y es difícil pensar en el volumen de trabajo que supone clasificar e inventariar a miles de posibles acreedores y en el caso de grandes empresas relacionar todos los activos, con esa premura. Esa prisa por emitir el informe choca después con un "iter" judicial en el que deben resolverse multitud de incidentes (bien es cierto que se han recortado enormemente las vistas), en definitiva, ese apresuramiento puede estar en el origen de muchos de ellos. El legislador ha optado, en uno de los muchos parches que ha ido poniendo a la norma, por incluir una información previa destinada a combatir algunos errores como lo aritméticos o las omisiones, pero obviando hacer referencia a las consecuencias de los posibles incumplimientos por parte de la administración del concurso a la hora de subsanarlos y sobre la que en un principio no hay recurso en la medida en que es la administración la que los resuelve. En cualquier caso, supone un avance en la buena dirección, aunque solo sea por evitar impugnaciones y en definitiva alargar el procedimiento.

El segundo, que lo dificulta en gran medida, es la circunstancia de tratarse de un procedimiento que no trata sobre algo parado, quieto. Muy al contrario, los concursos están más que vivos en el caso de las personas físicas, aunque muy a menudo ostentan la misma condición en el caso de las personas jurídicas, de ahí que lo que parece terminado, no lo está. Es frecuente que otros procedimientos conectados con el concurso sobre todo de ámbito administrativo se resuelvan en momentos posteriores, lo 
que obliga a incluirlos en el informe. Es por este motivo que el informe semeja una criatura viva, que, muy a menudo, se desarrolla de manera que la propia administración del concurso difícilmente puede prever.

Todo lo antedicho, se refleja en la propia redacción del texto normativo, que abunda en adiciones y reformas y que aconsejaría a mi juicio la redacción de una nueva ley. En realidad, en este como en otros ámbitos lo verdaderamente interesante es comprobar a través de la experiencia (la jurisprudencia en materia concursal es abrumadora, debido a la reciente crisis económica) lo que funciona y lo que no. Y, por tanto, creo que ahora es el momento de hacer una nueva ley que permita que los procedimientos cumplan con el verdadero fin para el que se creó el concurso, que no es otro, que la satisfacción de los acreedores, pero consiguiendo en la medida de lo posible la supervivencia económica de los concursados.

\section{REFERENCIAS BIBLIOGRÁFICAS}

Alonso Espinosa, Francisco José. "El informe de la administración concursal: un intento de clarificación sistemática”, Revista de Derecho Concursal y Paraconcursal 19 (2013): 101-114.

Conde Fuentes, Jesús. "La impugnación de inventario y de la lista de acreedores (provisional y definitiva)". Revista General de Derecho Procesal 33 (2014). https://www.iustel.com/v2/revistas/detalle_revista. asp?id_noticia $=414527$

Gimeno-Bayón Cobos, Rafael y Jacinto Gimeno Valentin-Gamazo. “Algunas cuestiones sobre la comunicación de créditos concursales”. Revista de derecho concursal y paraconcursal: Anales de doctrina, praxis, jurisprudencia y legislación 12 (2010): 219-253.

Noval Pato, Jorge. El informe de la administración concursal. Madrid:

La Ley, 2008. 
Ruiz Monge, Laura y Luís Franco Betegón. "La legitimación pasiva en la demanda incidental de impugnación del informe de la administración concursal”. Diario La Ley 7466 (2010)

Tomás Cuéllar Montes Área de Derecho Mercantil Departamento de Derecho Privado Facultad de Ciencias Económicas y Empresariales Universidad de Extremadura Avda. de Elvas, s. $n$. Badajoz (España) tcuellarm@unex.es https://orcid.org/oooo-0002-9447-5079 